\title{
Peertechz
}

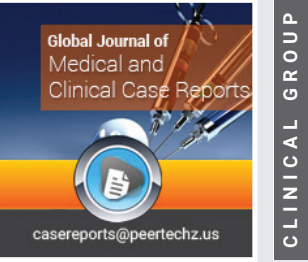

\section{Posterior aortopexy is the option}

\author{
Abdullah Al-Shamrani ${ }^{1 *}$ and Ahmed Elwy ${ }^{2}$ \\ 1Department of Pediatrics, Prince Sultan Military Medical City (PSMMC), AlFaisal University, Riyadh, \\ Saudi Arabia \\ ${ }^{2}$ Pediatric Cardiac Surgeon, Prince Sultan Cardiac Center, PSCC, Saudi Arabia
}

Received: 27 February, 2021

Accepted: 12 March, 2021

Published: 13 March, 2021

*Corresponding author: Abdullah Al-Shamrani, Department of Pediatrics, Prince Sultan Military Medical City (PSMMC), AlFaisal University, Riyadh, Tel: +966-14777714; Ext-25452; Fax: 24603; P.O. Box 7897, Riyadh 11159, Saudi Arabia,

E-mail:dr.alshamrani99@gmail.com

ORCID: https://orcid.org/0000-0001-7157-1706

Keywords: Malacia, Tracheomalacia, Double aortic arch, Stridor, Wheeze, Aortopexy

https://www.peertechzpublications.com

Check for updates

\section{Abstract}

Tracheomalacia is the abnormal collapse and flaccidity of the supporting tracheal cartilage, leading to a reduction in the caliber of the anterior-posterior airway. Tracheomalacia is common after cardiac compression or tracheoesophageal fistula. In the severe type, tracheomalacia may lead to significant morbidity, especially if encountered at a younger age or in a critical area, such as the distal part of the trachea. We report two cases that did not improve after initial cardiac surgery with persistent airway narrowing of more than $80 \%$, requiring prolonged ventilatory support. Both cases were difficult to manage but eventually showed a significant improvement after posterior aortopexy, which helped to wean them off the ventilator and produced marked clinical and radiological improvement. Both cases had residual malacia that was clinically presented as persistent audible wheezing and recurrent chest exacerbation. The diagnostic and therapeutic options for both cases are discussed.

\section{Abbreviations}

PICU: Pediatric Intensive Care Unit; PSMMMC: Prince Sultan Medical Military City; CPAP: Continuous Positive Airway Pressure; PEEP: Positive End Expiratory Pressures

\section{Introduction}

Malacia is an abnormal collapse of the airway walls [1]. There are three main types of malacia: laryngomalacia, tracheomalacia and bronchomalacia [2]. Laryngomalacia is a common pediatric problem that often presents with stridor's breath a few weeks after delivery and subsides by the first year in the majority of cases. Laryngoma is often a self-limited condition unless it affects feeding, breathing or growth. Reflux therapy is the first-line therapy if the condition affects feeding, breathing, or growth, followed by epiglottoplasty or other options, as indicated by the laryngologist. Tracheomalacia often affects the distal third of the trachea, and the lesion typically occurs in infants and young children. There are two main types of tracheomalacia [3].

\section{Primary (rare)}

This rare type is characterized by congenital absence or abnormal compliance of the cartilaginous part of the tracheal lumen.

\section{Secondary (common)}

This type is due to tracheoesophageal fistula, cardiac or mediastinal compression, or prolonged intubation. In the majority of patients, the tracheal cartilage normalizes as the airway enlarges, and symptoms may resolve with time and often by late childhood [4]. Clinical symptoms can range from minor expiratory stridor with typical barking cough, recurrent/ persistent wheezy chest, or severe respiratory distress episodes leading to apnea $[5,6]$. Aortopexy was proven to be helpful in severe types of tracheomalacia [7,8], whereas bronchomalacia is a rare condition that is often segmental and secondary to other conditions, such as cardiac compression.

\section{Case report (1)}

A 6-month-old girl, a product of full-term, normal, vertex delivery, presented with poor weight gain and interrupted feeding with signs of respiratory distress. Later, at the age of three months, she was diagnosed with congenital heart disease with a preoperative diagnosis of type 1 truncus arteriosus with severe truncal valve stenosis and regurgitation, and the chest 
CT scan showed bronchial vascular compression on the left main bronchus. Then, cardiac surgery was performed at the age of 6 months. The patient had a long postoperative course due to repeated failed extubations and persistent left lung collapse, and CT and virtual bronchoscopy showed that the left main bronchus was compressed between the anterior right pulmonary and posterior descending aorta. Bronchoscopy also showed a pulsatile left main bronchus with bronchomalacia extending to the distal bronchi. The decision was made among the pediatric cardiac surgery and pulmonology teams to go for posterior aortopexy of the descending aorta to take the aorta away from the left bronchus. Aortopexy was performed through a left thoracotomy operation. Intraoperative bronchoscopy showed immediate marked improvement in the patency of the left main bronchus pre- and postposterior aortopexy. The patient had a smooth postoperative course and was extubated on the $4^{\text {th }}$ postoperative day. The left lung remained fully inflated with no further collapse until home discharge 3 weeks later (Figures 1,2)

\section{Case report (2)}

Patient information: A 4-year-old boy born at term through a spontaneous vertex delivery presented with respiratory distress, which was diagnosed as transient tachypnea osf the newborn. Two days after birth, he had severe respiratory distress and audible inspiratory stridor for which he required Continuous Positive Airway Pressure (CPAP) followed by intubation and mechanical ventilation due to a high $\mathrm{PCO}_{2}$ level.

Diagnostic assessment: The patient was transferred from Al-Kharj (a secondary hospital) to Prince Sultan Military Medical City (PSMMC) for further evaluation. At PSMMC, he had an initial septic work up, and all values were negative. RSV was negative at that time in the peak of winter, even though stridor was not a presentation of common viral illness, including RSV, for which the intensivist consulted the pulmonologist for flexible bronchoscopy. A flexible bronchoscope $2.8 \mathrm{~mm}$ in size was introduced under light anesthesia through an ETT of $3.5 \mathrm{~mm}$. The procedure was performed in the PICU under conscious sedation, and the finding was a marked narrowing of the distal part of the trachea immediately above the carina. The airway was clearly pulsatile, with the recommendation to rule out vascular compression [bronchoscopy picture Figure 3]. The diagnosis of vascular ring was further supported by the presence of indentation of the esophagus during the upper gastrointestinal study and CT angiography.

A- Bronchoscopy picture of the distal main trachea, severe narrowing, just above the carina B- Marked improvement after the intervention with a PEEP of $12 \mathrm{~cm}$ of water (Figure 4).

Flexible bronchoscopy was conducted to confirm severe tracheomalacia with more than $90 \%$ narrowing of the tracheal lumen when it appeared as a pulsatile airway approximately 1 $\mathrm{cm}$ above the carina (length $1.5 \mathrm{~cm}$ ). The finding of a complete vascular ring was confirmed by CT angiogram, which showed a dominant, posterior, right-sided aortic arch and a smaller, anterior, left-sided aorta.

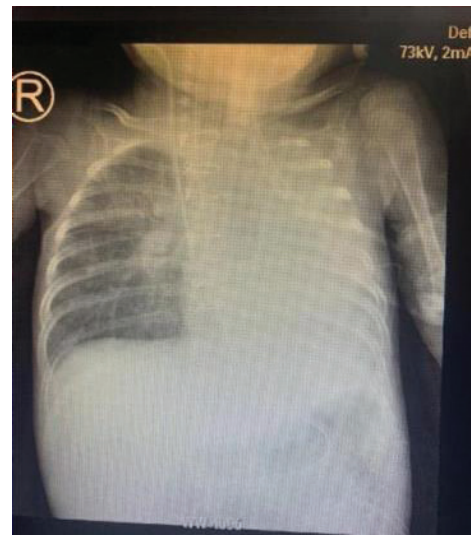

Figure 1: Chest X-ray: AP film, with a total collapse of the left-sided lung and secondary hyperinflation of the right-sided lung. ETT was performed in the usual position with evidence of central line, NJ tube, and midline sternotomy wires.

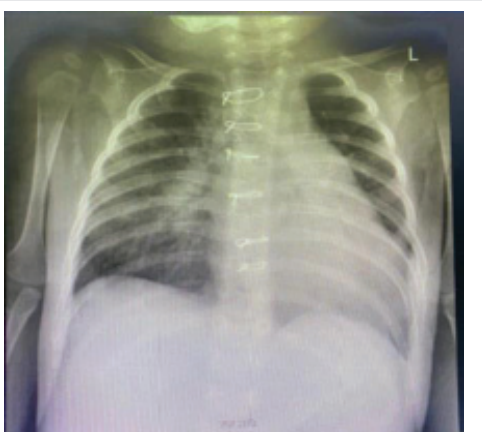

Figure 2: Chest X-ray: AP film, midline sternotomy wires, marked improvement in the aeration of the leftsided lung with some residual collapse on the left lower lobe and compensatory hyperinflation of the right lung with evidence of airspace lesions in the right middle zone.

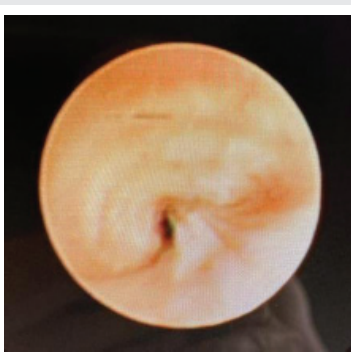

A - Before intervention

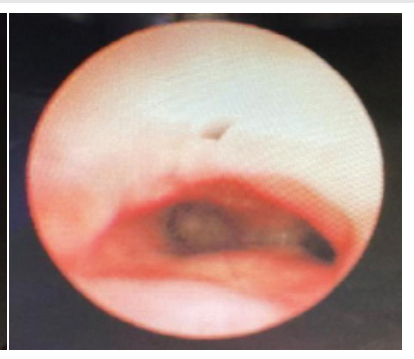

B. After intervention
Figure 3: Bronchoscopy pictures.

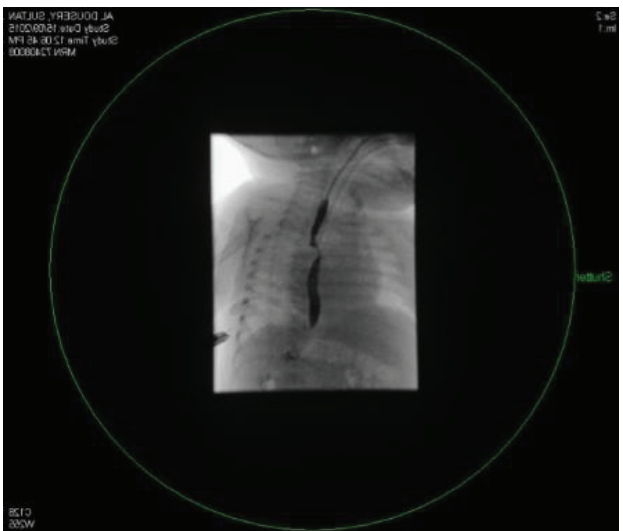

Figure 4: Upper gastrointestinal contrast study showing bilateral anterior and posterior indentation of the esophagus at the midportion with evidence of reflux disease. 


\section{Therapeutic intervention}

The patient underwent vascular ring repair as resection of the anterior aortic arch. Although he showed good signs of recovery, he unfortunately failed extubation several times despite good preparation and was in a low ventilatory setting with immediate stridrous breathing and significant desaturation.

Repeated events suggested a mechanical problem, and the patient remained ventilated for $14 \mathrm{~m}$ in the PICU. Repeated bronchoscopy showed residual narrowing of at least $80 \%$ at the site of the surgery, which did not respond well to increasing BEEP or bagging in the operation room. This case was discussed during the Saudi Pediatric Pulmonology Cross Country Round, at multiple case conferences, and with an airway expert at the Grand Ormond Street Hospital international medical center.

The recommended options were stenting, tracheostomy, and posterior aortopexy. Each option has pros and cons, but the majority advise posterior aortopexy. Repeated CT angiogram and bronchoscopy showed persistent narrowing of the distal part of the trachea by approxsssimately $80 \%$, with a marginal improvement in the narrowing of the airway lumen after the initial surgery. Posterior aortopexy was performed, and the patient showed significant improvement and extubated easily. He is thriving well but has recurrent chest infection and noisy breathing that usually worsens with upper respiratory tract infection, especially in the winter. The two patients were in the hospital in the second year due to chest exacerbation, and in the fourth year, they had two, very limited, short admissions and did not require PICU admission (Figure 5).

\section{Discussion}

Tracheomalacia is a common reason to consult pediatric pulmonologists, especially at cardiac centers. The presentation of patients with suspected tracheomalacia depends on the severity of malacia, location, length of segment, age and associated anomalies, which could vary from asymptomatic to ventilatordependent or persistent lung collapse [3]. As the common site is the distal third of the trachea in moderately severe cases, children will present with persistent wheezing

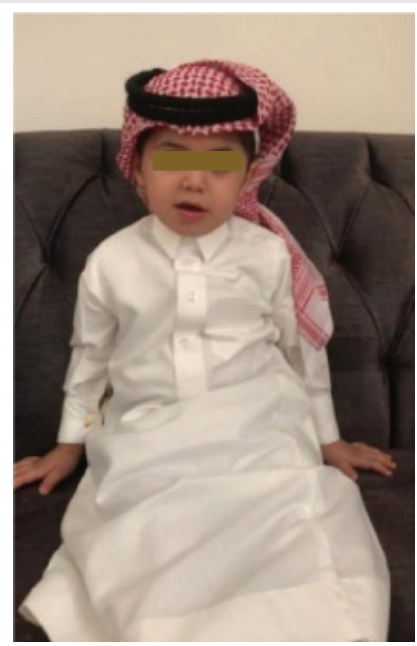

Figure 5: Sultan pictured in one of his usual follow-ups at the OPD clinic. and a barky cough that does not respond to asthma therapy [4]. In addition, the cough may worsen after the use of a bronchodilator or a viral respiratory illness [5]. Severe cases manifest as episodic paroxysmal cough, cyanotic episodes leading to the loss of consciousness, apnea, and even cardiac arrest, similar to pertussis-like disease, and the initial assessment depends on the severity and potential underlying cause [6]. Wheezing is the usual presentation, especially when excited, such as playing, laughing or due to chest infection. However, some cases could present with stridor if the malacia is long and affects the upper third of the trachea as it is outside the thoracic inlet. Bronchomalacia is commonly observed in the cardiac center, often due to vascular compression from cardiac chamber enlargement or vascular compression, leading to variable abnormalities on the left-sided chest ranging from hyperinflation when there is partial compression to near or total collapse of the left-sided lung. The diagnosis is easy and can be confirmed by flexible bronchoscopy with minimal sedation, but treatment depends on the severity. Mild cases often resolve spontaneously with no intervention $[5,6]$. Moderate to severe cases require supportive therapy, suctioning and chest physiotherapy, lower thresholds for starting antibiotics, minimal use of bronchodilators and potential CPAP therapy during exacerbation, and in severe cases, tracheopexy, tracheoplasty and stenting of the airway have been reported in the literature with variable and limited indications [7-10].

Posterior aortopexy has been reported to be a useful and safe method to relieve airway compression in pediatric patients [9-14]. Residual malacia was reported as common and should be suspected [12-15].

\section{Conclusion}

Vascular compression of the left main bronchus is not uncommon in the pediatric age group, especially in those with congenital heart disease. Posterior aortopexy has proven to be a safe, effective, and simple technique for managing a complex pathology and preventing further irreversible damage to the airway. It can help to avoid more complex interventions that could increase both morbidity and mortality. Residual malacia should be considered a common complication, and the management of such cases is a real challenge that requires a multidisciplinary team.

\section{Acknowledgments}

We would like to thank American Journal Experts for editing the manuscript.

\section{References}

1. Carden KA, Boiselle PM, Waltz DA, Ernst A (2005) Tracheomalacia and tracheobronchomalacia in children and adults: An in-depth review. Chest. 127: 984-1005. Link: http://bit.ly/2PYObxN

2. Vicencio AG, Parikh S (2006) Laryngomalacia and Tracheomalacia: Common Dynamic Airway Lesions. Pediatr Rev. 27: 33-35. Link: http://bit.ly/30DjLmF

3. McNamara VM, Crabbe DC (2004) Tracheomalacia. Paediatr Respir Rev. 5 : 147-154. Link: http://bit.ly/30AWkdN

4. Fraga JC, Jennings RW, Kim PC (2016) Pediatric Tracheomalacia. Semin Pediatr Surg. 25: 156-164. Link: http://bit.ly/38wbq8X 
5. Hysinger EB, Panitch HB (2015) Paediatric Tracheomalacia. Paediatr Respir Rev. 17: 9-15. Link: http://bit.ly/30Dpj0K

6. Dave S, Currie BG (2006) The role of aortopexy in severe tracheomalacia. J Pediatr Surg. 41: 533-537. Link: http://bit.ly/3bGUizk

7. Tytgat SHAJ, van Herwaarden-Lindeboom MYA, van Tuyll van Serooskerken ES, van der Zee DC (2018) Thoracoscopic posterior tracheopexy during primary esophageal atresia repair: A new approach to prevent tracheomalacia complications. J Pediatr Surg. 53: 1420-1423. Link: http://bit.ly/3l8eM73

8. Wright CD, Mathisen DJ (2018) Tracheobronchoplasty for tracheomalacia. Ann Cardiothorac Surg. 7: 261-265. Link: http://bit.ly/30AQTvr

9. Hester FS, Jason SC, Thomas EH, Visner ZD, Gary A, et al. (2019) Descending Aortopexy and Posterior Tracheopexy for Severe Tracheomalacia and Left Mainstem Bronchomalacia. Semin Thorac Cardiovasc Surg. Autumn. 31: 479485. Link: http://bit.ly/3qDL7Un

10. Adil A , Adnan M AA, Faiz YB (2017) Stents for airway strictures: selection and results. Journal of Thoracic Disease. 9: 116-121. Link: Link: http://bit. ly/3lkUkjD
11. Kikuchi S, Kashino R, Hirama T, Kobayashi H, Abe T (1999) Successful treatment of tracheomalacia associated with esophageal atresia without a tracheoesophageal fistula by aortopexy: report of a case. Surg Today. 29: 344346. Link: http://bit.ly/38wbOUX

12. Weber TR, Keller MS, Fiore A (2002) Aortic suspension (aortopexy) for severe tracheomalacia in infants and children. Am J Surg. 184: 573-577. Link: http://bit.ly/20J6ma4

13. Van der Zee DC, Straver M (2015) Thoracoscopic aortopexy for tracheomalacia World J Surg. 39: 158-164. Link: http://bit.ly/3qDLjmz

14. Arcieri L, Serio P, Nenna R, Maurizio MD (2016) The role of posterior aortopexy in the treatment of left mainstem bronchus compression. Interactive Cardio Vascular and Thoracic Surgery. 23: 699-704. Link: http://bit.ly/3t8Aafh

15. Jo SW, Frain ZB, Leah, Gary V, Smithers Charles J (2020) When to consider a posterolateral descending aortopexy in addition to a osterior tracheopexy for the surgical treatment of symptomatic tracheobronchomalacia. J Pediat Surg. 55: 2682-2689. Link: http://bit.ly/3ewXGyr

\section{Discover a bigger Impact and Visibility of your article publication with} Peertechz Publications

\section{Highlights}

* Signatory publisher of ORCID

* Signatory Publisher of DORA (San Francisco Declaration on Research Assessment)

- Articles archived in worlds' renowned service providers such as Portico, CNKI, AGRIS, TDNet, Base (Bielefeld University Library), CrossRef, Scilit, J-Gate etc.

* Journals indexed in ICMJE, SHERPA/ROMEO, Google Scholar etc.

* OAI-PMH (Open Archives Initiative Protocol for Metadata Harvesting)

* Dedicated Editorial Board for every journa

* Accurate and rapid peer-review process

* Increased citations of published articles through promotions

* Reduced timeline for article publication

Submit your articles and experience a new surge in publication services (https://www.peertechz.com/submission).

Peertechz journals wishes everlasting success in your every endeavours.

Copyright: @ 2021 Al-Shamrani A, et al. This is an open-access article distributed under the terms of the Creative Commons Attribution License, which permits unrestricted use, distribution, and reproduction in any medium, provided the original author and source are credited. 